\title{
Chemistry and Tensile Properties of a Recycled AA7050 Via Spray Forming and ECAP/E
}

\author{
Alexandre Hyodo ${ }^{\text {a*, Claudemiro Bolfarini }}{ }^{\mathrm{b}}$, Tomaz Toshimi Ishikawa ${ }^{\mathrm{b}}$ \\ ${ }^{a}$ Flight Test Department, Embraer S. A., Av. Brigadeiro Faria Lima, 2170, \\ CEP 12227-901, São José dos Campos, SP, Brazil \\ ${ }^{\mathrm{b}}$ Department of Materials Engineering, Federal University of São Carlos - UFSCar, \\ Rod. Washington Luis, Km 235, CEP 13356-550, São Carlos, SP, Brazil
}

Received: September 25, 2011; Revised: April 6, 2012

\begin{abstract}
The aim of this work is to evaluate the conjugation of advanced processing techniques, such as spray forming, extrusion and ECAP as a processing route for reuse of machining chips generated during aircrafts manufacturing parts from AA7050-T7451 raw material plates supplied according to AMS $4050 \mathrm{H}^{1}$. In this way, the sprayforming process was used for remelting, and billet production, followed by extrusion and ECAP. At the end of the process, an artificial aging according to AMS $2772 \mathrm{E}^{2}$ was conducted. An assessment of chemical composition, microstructure, and mechanical properties evolution throughout the process were performed. The results have showed that this proposed route may be used as a potential technological route for secondary aluminum source. For extrusion route for overaged condition, $144 \mathrm{MPa}$ yield strength and $14 \%$ of elongation was attained. Beside this, at this stage of work, was verified that the hot extrusion process is more effective for reduction of porosity and microstructure development than ECAP, but on the other hand this one has reduced porosity dispersion significantly for the extrusion parameters adopted. The adopted homogenization schedule, followed by artificial aging after has resulted in excessive grain growth.
\end{abstract}

Keywords: recycling, aerospace alloy, machining chip, re-use

\section{Introduction}

The contribution of aluminum alloys on airframe building is very extensive. Sheet metals (bare and clad), forging (die and precision forging) ${ }^{3}$, investment castings, extrusions ${ }^{4}$ and wrought rolled plates ${ }^{5-7}$ are some of most common technologies available. Considering the total aircraft weight, the global buy-to-fly ratio is approximately two which is the relation between the amounts of material necessary to manufacture an airframe part. But the technology breakdown of this ratio for machining is more representative, for this work. Despite the availability of several technologies used to manufacture airframe parts ${ }^{8}$ and new aluminum alloys overcoming new restrictive requirements ${ }^{9}$, machining process is remarkable used due to its flexibility (e.g., simulation and CNC programming), relatively low cost (e.g., process and tooling) and robustness. But, from this standpoint, the machining efficiency is low when considering the amount of material necessary to machine a single part, which is about ten percent in weight, resulting in a buy-to-fly ratio around nine.

The life cycle of aluminum (LCA) or flow of aluminum starts with mining of bauxite up to smelting of alumina to obtain the primary aluminum, which is poured into several basic shapes that will be processed as semi-manufactured goods and after processed into finished goods. Scraps from fabrication and manufacture of finished goods are generally recycled and is called new scrap ${ }^{10}$. In this way, the direct deployment of the end of primary aluminum alloys cycle

*e-mail: hyodo.alexandre@gmail.com (made from primary aluminum), is the environment impact caused by new scrap, machining chips and its disposal need.

The process of converting scrap aluminum to semi-finished products is referred as secondary aluminum process ${ }^{11}$. Compared with primary aluminum process, producing one ton of aluminum from recycled materials takes $5 \%$ of the energy required to refine a ton of aluminum from bauxite ore ${ }^{12,13}$. In 1990 total aluminum production was around 28 million tones (with $29 \%$ recycled from scrap) and today the total is close to 56 million tones (with $32 \%$ recycled from scrap). By 2020 metal demand is projected to have increased to around 97 million tones (with around $32 \%$ recycled from scrap). Today, around $50 \%$ of the scrap is old scrap (i.e. scrap from end-of-life products) ${ }^{14-16}$. Besides the need for increasing the secondary aluminum content on total aluminum available to produce goods, there should have an accurate decision making model for costs and demand forecast, and an indicator related to the environmental performance of material ${ }^{17,18}$. Another recycling approach is the end-of-life recycling approach, with the former approach is, encourages manufacturers, policy-makers and other decision-makers to evaluate real performance and improve the design and management of products, including their disposal and recycling. This forward- looking perspective supports sustainable development.

In aerospace market, the aging and obsolescence of aircraft fleet represents an "urban aluminum mine" and the reuse will lower carbon footprints. In order to be well 
succeed, an Alloy Recycling Index, which represents the recovering the maximum stored energy invested in the alloy, carbon footprint (Quantitative); and Alloy Recycling Production Index have been developed, that means how ease of producing from recycled remelts (Qualitative). Aluminum alloys from 2xxx series and 7xxx are most often used in aerospace industries but as they have high $\mathrm{Cu} / \mathrm{Zn}$ ratio, they are difficult to recycle together. Therefore, pre-shredded segregations into $2 \mathrm{xxx}$ and $7 \mathrm{xxx}$ groups for remelting is recommended, and the management of the alloying elements $\mathrm{Ag}, \mathrm{Be}, \mathrm{Bi}, \mathrm{Pb}, \mathrm{Li}$ and grain refiners $\mathrm{Cr}, \mathrm{Zr}, \mathrm{V}^{19}$ may enable their recycling process.

Considering the exposed and the lack of information on recycling $7 \mathrm{xxx}$ aluminum alloy series, there is a technological opportunity to be evaluated. Despite the amount of works published on technologies that will be referenced in this work, there is not a direct correlation with recycling process.

The scope of this work is the assessment of a technological route, where the suitable combination of effective processes may enable a way to reincorporate the machining chips, arouse from machining of aluminum alloy plates used to produce airframe parts, to the main stream process of an airframe manufacturer.

In this project, sprayforming process is used for machining chips remelting. The load is remelted in an induction furnace, and then the molten metal is slowly poured through a conical tundish into a quartz capilar, driven by metallostatic column. The molten metal enters the sprayforming chamber as a thin free-falling stream and is broken up into droplets by an annular array of inert gas $\left(\mathrm{N}_{2}\right)$ flow, and these droplets then proceed downwards, accelerated by the gas flow to impact onto a substrate. The process is arranged such that the droplets strike the substrate whilst in the semi-solid condition, this provides sufficient liquid fraction to keep the solid fraction together. Deposition process continues, gradually building up a spray formed deposit of metal on the substrate.

In order to change the as-deposited microstructure, hot extrusion process was adopted as the main process due to compressive forces and axis symmetry involved, process parameters flexibility and relatively low cost tooling. It seems that this process will help to deal with deposit brittleness and foster the need of microstructure evolution in an almost one step process.

Sharma et al. ${ }^{20}$ succeed to develop a work similar to this but with the purpose to evaluate the hardening mechanisms in spray formed $\mathrm{Al}-\mathrm{Zn}-\mathrm{Mg}-\mathrm{Cu}$ alloys with additions of chromium, zinc and scandium. The steps adopted were the same, a modified sprayforming set up in order to obtain a deposit, followed by thermo mechanical processing and heat treatment but, it seems that was not included the extrusion process parameters evaluation in scope of this work.

But due to sprayforming equipment and tooling limitations we did not succeed to perform more than $5: 1$ of extrusion ratio at a deformation rate $(\mathrm{d} \varepsilon / \mathrm{dt})$ about $0.20 \mathrm{~s}^{-1}$. In this way, the equal channel angular pressing/extrusion (ECAP/E) came as an option to improve the thermo mechanical processing. ECAP/E was chosen due to its potential reduction in grain size according to results obtained in several works available in literature ${ }^{21-27}$ that has developed the ECAP/E concept and since then has explored its potentialities from wrought raw materials, including the AA7050. For this work, there is a special interest for this process mainly related to several deformations without changing the cross sectional area and possibility of grain size reduction. And according to Furukawa et al. ${ }^{23}$, the processing route $\mathrm{B}_{\mathrm{C}}$ provides the most rapidly microstructural evolution.

The scope of this work corroborates with the sustainability concepts practiced by Embraer and look towards build the vision that "a sustainable company is one that generates profit for its shareholders, while at the same time protecting the environment and improving the lives of those with whom it interacts" 28 . In addition, other projects $^{29,30}$, has highlighted the main drivers concerning the design of new alloys for application directly from recycled aluminum alloys, and presents some guidelines that support these initiatives.

\section{Experimental}

The alloy chosen for this work was a three inches thick plate of AA7050-T7451 purchased according to AMS $4050 \mathrm{H}^{1}$. For the purpose of this work, the machining chips were specially segregated in machining shop and shipped to laboratory facilities. Relevant information like chemical composition, mechanical properties, lot and heat number were traced based on supplier certificate of quality, which was assumed as a baseline.

As pointed before this, work consists on remelting the machining chips via sprayforming and obtains a deposit, followed by two processing routes that were developed: a hot extrusion process and ECAP/E. The use of homogenization was adopted when appropriate, and finalized via artificial aging. Chemical analysis, microstructural investigation, and mechanical properties measurements were performed when appropriate.

Before each batch of sprayforming, approximately $4.0 \mathrm{~kg}$ of the machining chips were manually withdrawn from the laboratory stock, washed with alkaline cleaner, rinsed and carefully dried with propane torch flame manually.

The machining chips loaded on alumina crucible were induction heated for melting above $\mathrm{T}_{\text {Liquidus }}\left(630^{\circ} \mathrm{C}\right)$. Then the material was poured $\left(\mathrm{T}_{\text {Pouring }}: 790^{\circ} \mathrm{C}\right)$ in a $2 \mathrm{~L}$ tundish linked to the sprayforming chamber with a capilar with $8 \mathrm{~mm}$ on top and $6 \mathrm{~mm}$ in the bottom and $80 \mathrm{~mm}$ long. A $300 \mathrm{~mm}$ flight distance was adopted; surrounded by 10 bar $\mathrm{N}_{2}$ pressure gas flow from sixteen nozzles. The substrate rotation speed was $60 \mathrm{rpm}, 15-20 \mathrm{~mm}$ of eccentricity in order to obtain a flat top deposit; and the average time elapsed for deposition was 50 seconds. The deposit obtained was approximately $250 \mathrm{~mm}$ in diameter and 25 to $40 \mathrm{~mm}$ thick. The final useful weight of deposit was about $3.0 \mathrm{~kg}$, in average. The losses are mainly related to flash and overspray.

Determination of chemical composition of sprayforming deposit was performed using optical emission spectrometry with inductively coupled plasma (ICP OES) VISTA machine model. The composition was compared former raw material supplied to OEM, only for zinc, magnesium, copper, and zirconium. 
In order to reduce porosity in recycled material the direct hot extrusion process was chosen due to its intrinsic characteristics like relatively low cost tooling, process parameters flexibility (e.g., temperature, and ram speed), and compressive stress during the process. Using the $400{ }^{\circ} \mathrm{C}$ curve as a reference, there are three distinct regions in these curves: in the first region (I) a transient region where it is not likely that an actual extrusion process has effectively started and due to small increase in stress and might be more related to change in as deposited morphology. In the following region (II) there is a linear type of increase in extrusion stress up to the stress peak. The steady-state region III shows a decrease in stress time-history - Figure $1^{31}$.

The billets used for hot extrusion were withdrawn from initial deposit, machined in a lathe into a $25 \mathrm{~mm}$ diameter cylinder with approximately $50 \mathrm{~mm}$ length. Four direct hot extrusion temperatures $\left(360^{\circ} \mathrm{C}, 400^{\circ} \mathrm{C}, 405^{\circ} \mathrm{C}\right.$ and $\left.445^{\circ} \mathrm{C}\right)$ were used, the aimed reduction ratio was $5: 1$ followed by water cooling at room temperature. The DL 60000 EMIC Universal Testing Machine with 60 ton maximum load capacity and ram speed from 0.01 up to $100 \mathrm{~mm} / \mathrm{min}$ capability, coupled with an auxiliary controlled heating system was used. Before each extrusion, each billet was heated to the target extrusion temperature and hot soaked for approximately 10 minutes. The billet diameter was $15.8 \mathrm{~mm}$ and $52 \mathrm{~mm}$ long.

Following the extrusion process the material was machined in order to obtain tensile test small size specimens according to ASTM E8 "Standard Test Methods for Tension Testing of Metallic Materials" 35 . After extrusion, no additional heat treatment was carried out. The average values of the tensile properties: tensile strength, yield strength and elongation, are considered as a function of the extrusion temperatures and compared with the specification of the plate material. Another study in this route was performed by using two different extrusion ram speeds, at the same temperature, and the hardness Brinell test, using a using a $2.5 \mathrm{~mm}$ steel ball indenter with $62.5 \mathrm{kPa}$ load, was used to evaluate the mechanical properties evolution. And the OM, via average grain size change, throughout the proposed route, were used as a quick way to assess the effectiveness of microstructure change.

Due to limitation of extrusion ratio available for extrusion process in laboratory conditions, equal channel angular pressing/extrusion (ECAP) was adopted due to amount of deformation that may be attained with this

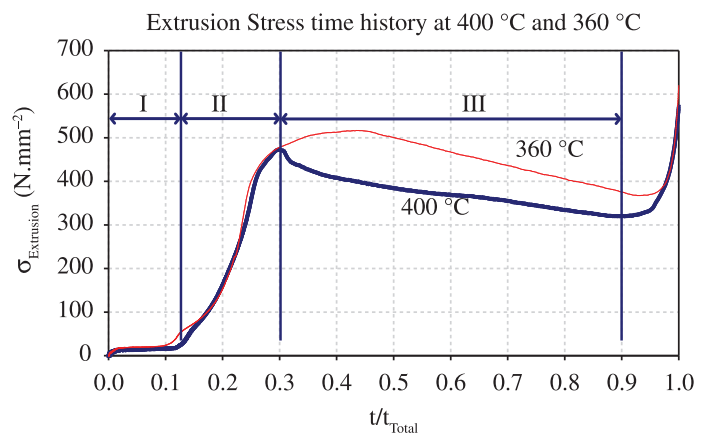

Figure 1. Stress versus time curve for two extrusion temperatures. shearing deformation process, without changing cross section area. After sprayforming, billets were withdrawn from the deposit, and milled machined to ECAP coupon dimensions, a $123 \mathrm{~mm}^{2}$ squared cross section, and $60 \mathrm{~mm}$ length. In order to perform the ECAP process, the Universal Testing Machine DL 60000 EMIC coupled with an auxiliary controlled heating system was adopted, and the ECAP route was $\mathrm{B}_{\mathrm{C}}$ (4 passes) at $300{ }^{\circ} \mathrm{C}$ with a $3 \mathrm{~mm} / \mathrm{min}$ ram speed and a channel angle $(\phi)$ of $110^{\circ}$.

After ECAP, coupons were sliced in squared samples with approximately $3.0 \mathrm{~mm}$ thick and these withdrawn samples were submitted to a two steps homogenization ( $420{ }^{\circ} \mathrm{C}$ for 4 hours and $470{ }^{\circ} \mathrm{C}$ for 8 hours). Followed by artificial aging heat treatment according to SAE Aerospace AMS 2772 $\mathrm{E}^{2}$.

The microstructural evolution from the sprayforming deposit up to heat treated material were evaluated via optical microscopy (OM), scanning and transmission electron microscopy (SEM and TEM) either for extruded and ECAP/E routes were evaluated.

Hardness Brinell was the method used for preliminary mechanical properties evaluation using a Heckert durometer with $2.5 \mathrm{~mm}$ steel ball indenter with $62.5 \mathrm{kpa}$ load.

A ZEISS Axio optical microscopy was used in order to evaluate the microstructural evolution during the stages of each route. The samples were prepared according to conventional metallographic preparation. Grinded with 320 , 600, 1200 sand paper and polished with diamond paste, and etched with Keller etchant for 15 to 20 seconds. The prepared samples were analyzed under several magnifications $(50 \times, 100 \times, 200 \times$, and 500×) and the intercept method, according to ATSM E 112 was adopted for average grain size determination ${ }^{37}$. The image analysis and statistics were performed with ImageJ 1.32 and Lumenera Infinity Analize release 4.6.0.

A Philips model XL30-TMP and XL30-FEG (field emission gun) equipped with Energy dispersive X-ray spectrometer (EDS) at UFSCar and a JEOL and Cambridge from Embraer has enabled to analyze further the regions identified in OM examination. Perform localized chemical analysis of microscopic second phase particles or regions within a sample. Energy Dispersive Spectrometer (EDS) micro-analysis was performed by measuring the energy and intensity distribution of X-ray signals generated by a focused electron beam on the specimen (EDS). With the attachment of the energy dispersive spectrometer, a qualitative elemental composition of materials was obtained.

For fracture surface of tensile specimens examined with higher magnification type of stress (tensile, shear, torsional), mode of fracture (ductile or brittle), direction of fracture propagation, area and mechanism of fracture initiation, processing related factors contributing to the failure, and other factors related to cause of failure.

A FEI TECNAI G2 F20 HRTEM and a Philips CM-120 transmission electron microscopy from Laboratório de Caracterização Estrutural from DEMa/UFSCar were used for specific analysis on Extruded and ECAP/E samples. The samples preparations were done by using a GATAN - Model 691 Precision Ion Polishing System. 


\section{Results and Discussions}

\subsection{Direct hot extrusion}

The "as sprayed" deposit may be characterized as circular shape and porous. The average mass of deposit is approximately $75 \%$ of the initial batch charge.

The optical microscope analysis of as-deposited microstructure shows equiaxed particles with average size of $50 \mu \mathrm{m}$ - Figure $2 \mathrm{a}$. The microstructure of deposit particles are characteristic from rapid cooling and solidification process, with the presence of lamellar phase at grain boundaries and a more homogeneous microstructure in the center region - Figure $2 b$, might be related to some excess of heating during pouring. And the porosity ranged from $2.6 \mu \mathrm{m}$ up to $400 \mu \mathrm{m}$, with an average size of $22 \mu \mathrm{m}$, and $36 \mu \mathrm{m}$ of standard deviation.

A second phase among the deposit particles is more evidenced under BSE/SEM analysis - Figure 3a. The EDS analysis had revealed that the second phase composition is similar to the main composition but with a higher copper content. They are more concentrated at triple points of particles and seem that this copper rich phase was shared during the early stages of deposit build up process. This mechanism is likely to be more understood and evidenced by its systematic presence in the necking region between two deposited particles. And on the deposited particle surface, as small and thin plate clusters can be seen in Figure $3 \mathrm{~b}$. This second phase, may evidence the boundaries of the former remelted metal droplet, and its presence matches with the morphology presented in the flat surface of Figure $3 \mathrm{~b}$ and the three dimensional aspect of pore surface in this same figure.

The specimens withdrawn near center region of spray forming deposit has showed the presence of some small dendrites growth clusters Figure $4 \mathrm{a}$ and some very tiny isolated spots - Figure $4 \mathrm{~b}$ has revealed the mix of microstructures developed during the built up of spray forming deposit.

This kind of microstructure formation shall not be present but as this material will be submitted to severe mechanical deformation; it is likely that this microstructure will be totally transformed in new texture.

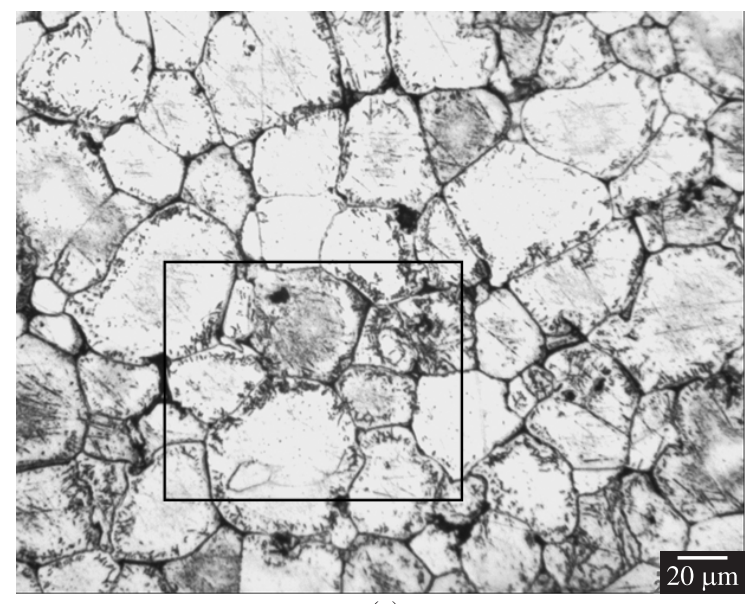

(a)

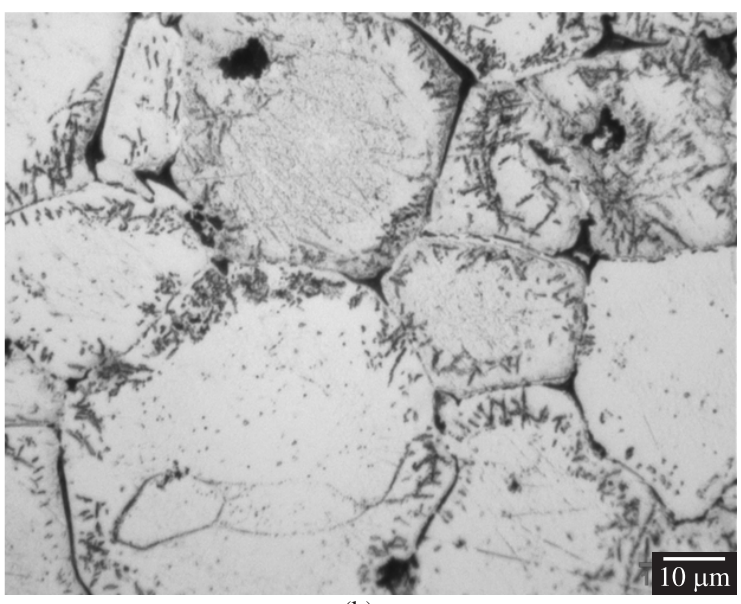

(b)

Figure 2. As-deposited microstructure analyzed with optical microscopy (a) with detail from the black box in (b) showing segregation in grain boundaries. Keller etching.

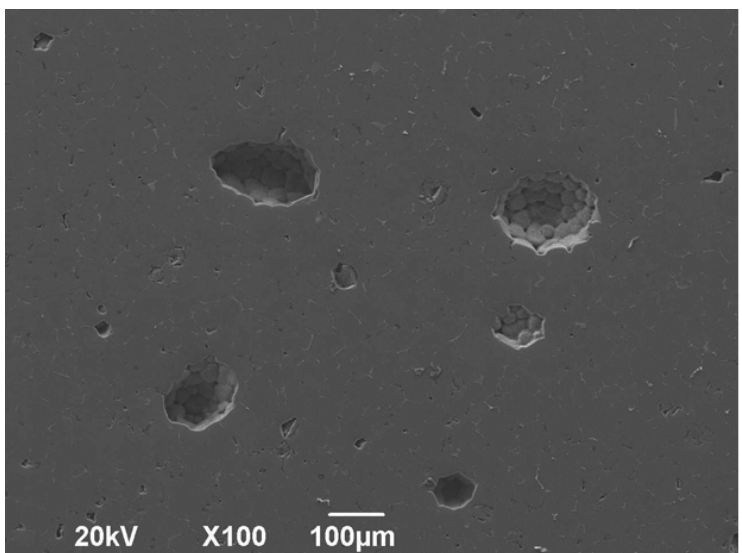

(a)

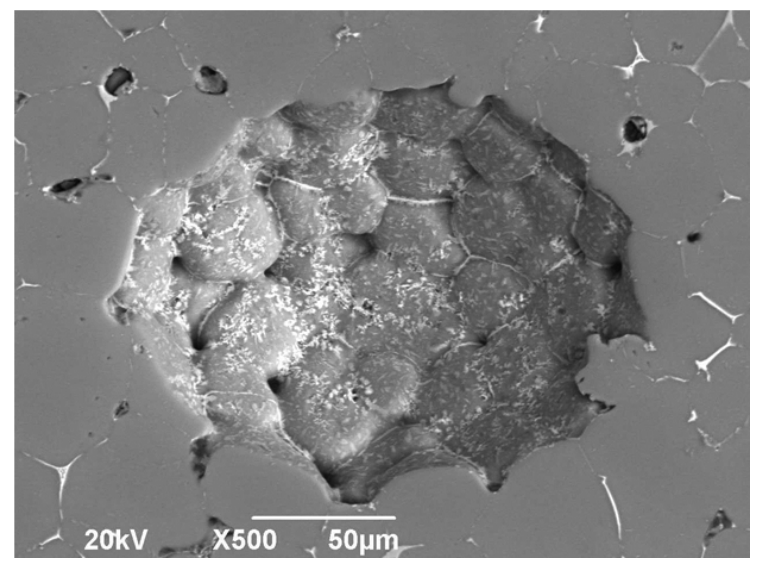

(b)

Figure 3. As-deposited microstructure analyzed under SEM analysis with BES (a). Deposit void showing a second phase between deposited particles with more magnification (b). Etchant: Keller. 
The microstructure evolution is evidenced from the compressed as-deposited condition in Figure 5. Optical microscopy of a longitudinal section showing the microstructure evolution during extrusion at $300{ }^{\circ} \mathrm{C}$ and $6 \mathrm{~mm} / \mathrm{min}$ ram speed. (a) compressed as-deposited. (b) as extruded. Etchant: Keller.a, to the as-extruded microstructure with homogeneous and elongated grains in Figure 5. Optical microscopy of a longitudinal section showing the microstructure evolution during extrusion at $300{ }^{\circ} \mathrm{C}$ and $6 \mathrm{~mm} / \mathrm{min}$ ram speed. (a) compressed as-deposited. (b) as extruded. Etchant: Keller.b. At the extruded conditions used, the grains seem to be in recovered condition and pores seem to be reduced.

Small specimens for tensile test according to ASTM E $8 / \mathrm{E}^{35}$ was performed for as-extruded condition only. The best average value obtained was $500 \mathrm{MPa}$ for extrusion temperature of $400{ }^{\circ} \mathrm{C}$, which lies below the specification value of the commercial plate.

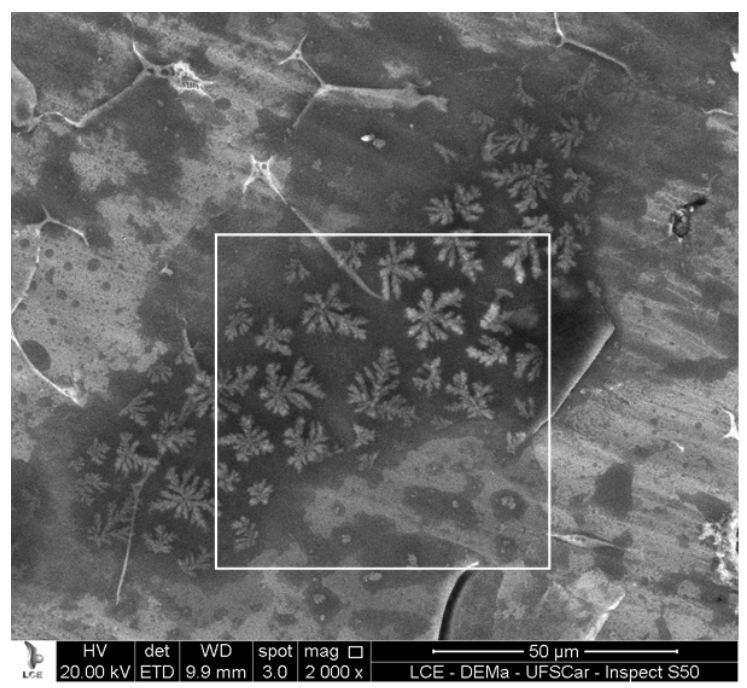

(a)
The extrusion temperature with smallest standard deviation was $405^{\circ} \mathrm{C}$. For the yield strength the best value was practically the same for the extrusion temperatures of $360{ }^{\circ} \mathrm{C}$ and $400{ }^{\circ} \mathrm{C}$, below the specification value of the commercial plate. The values obtained for elongation, in average, are higher than AMS $4050 \mathrm{H}^{1}$. Figure 6. Comparison of tensile properties of an as-spray formed and extruded material with and the AMS $4050 \mathrm{H}$. summarizes the results obtained, and reveals that the best result obtained for the yield strength attained was approximately $80 \%$ of the specification for the AA7050, with good elongation values higher than specification value. Concerning tensile properties results, there is a step reduction near $400{ }^{\circ} \mathrm{C}$, it is likely that this effect is somewhat related to $\eta$ precipitates dissolution ${ }^{36}$.The SEM analysis of specimens fractured surface, via SE source, shows typical ductile appearance With predominance of dimples, which was expected from the elongation values obtained Figure 7. SE/SEM

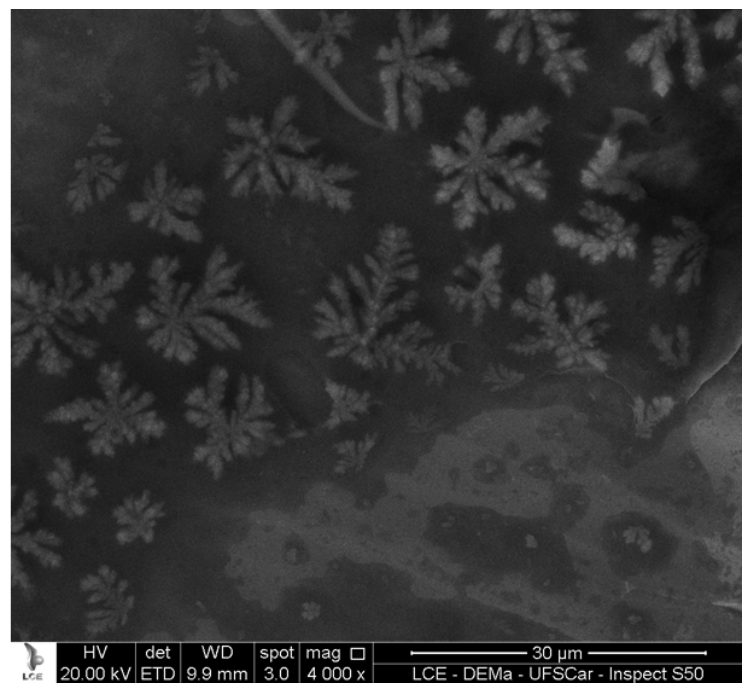

(b)

Figure 4. Dendrites presence in as-deposited microstructure (a). Detail of dendrites from white box region (b).

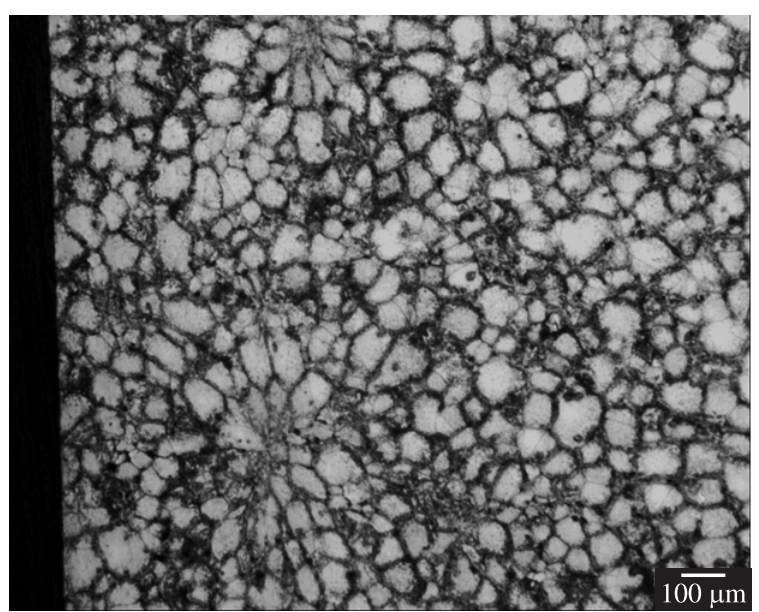

(a)

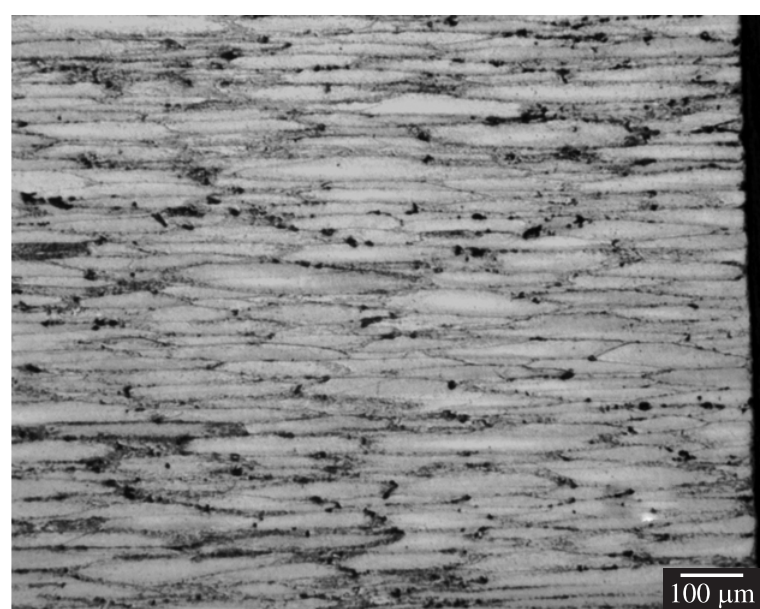

(b)

Figure 5. Optical microscopy of a longitudinal section showing the microstructure evolution during extrusion at $300{ }^{\circ} \mathrm{C}$ and $6 \mathrm{~mm} / \mathrm{min}$ ram speed. (a) compressed as-deposited. (b) as extruded. Etchant: Keller. 


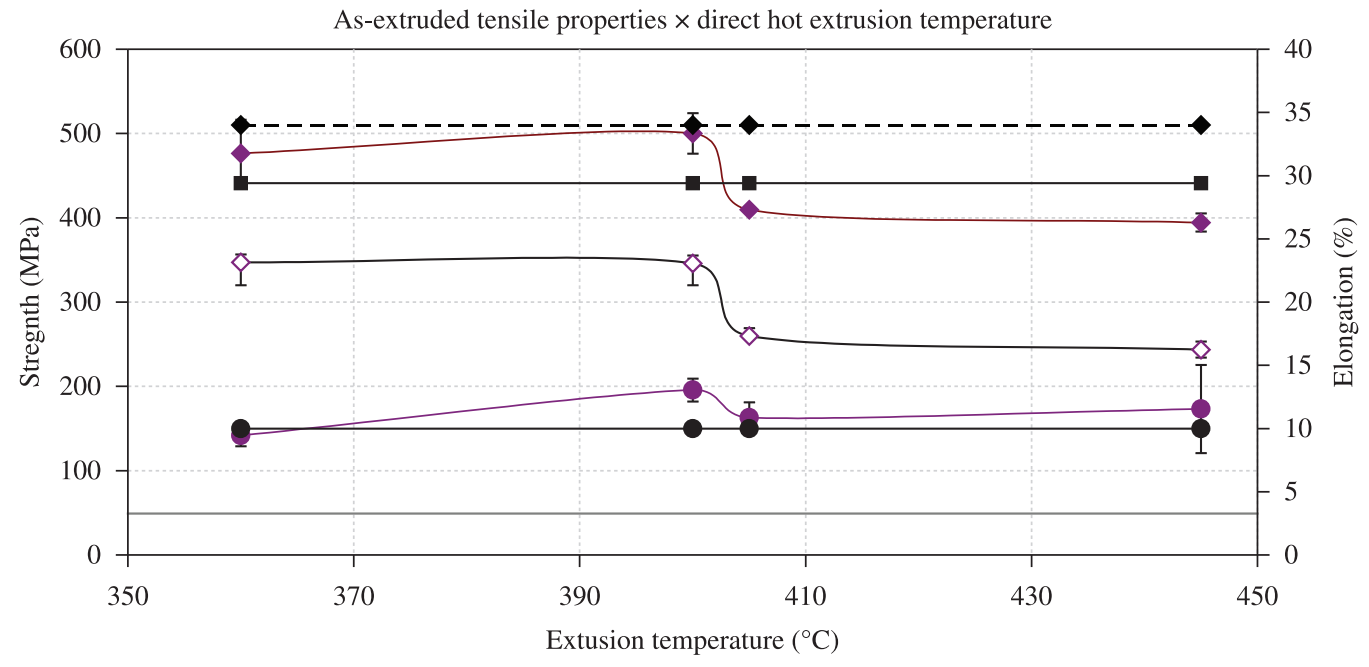

$$
\begin{array}{ll|}
\longrightarrow \checkmark \text { Yield Strenght }(\mathrm{MPa}) & - \text { Tensile Strenght (MPa) } \\
-\checkmark \cdot \text { AMS } 4050 \mathrm{H} \text { - Tensile Strength }(\mathrm{MPa}) & - \text { AMS 4050H - Yield Strength (MPa) } \\
- \text { Elongation }(\%) & - \text { AMS 4050H - Elongation (\%) } \\
\hline
\end{array}
$$

Figure 6. Comparison of tensile properties of an as-spray formed and extruded material with and the AMS $4050 \mathrm{H}$.

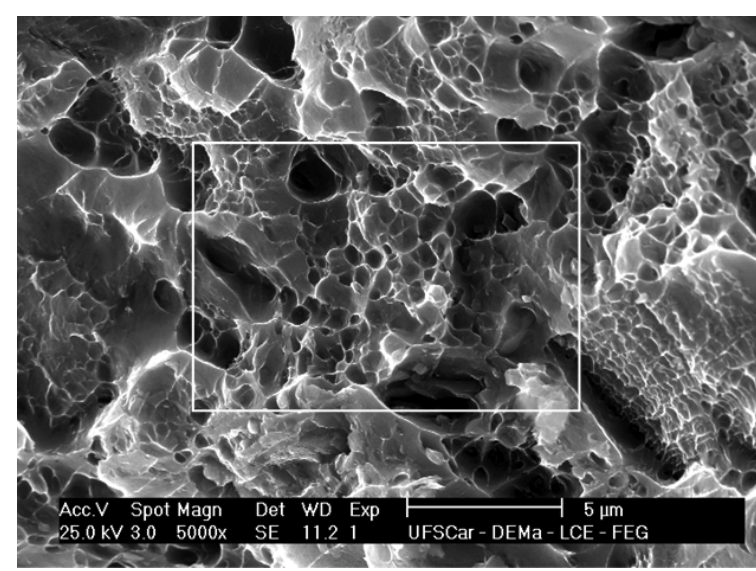

(a)

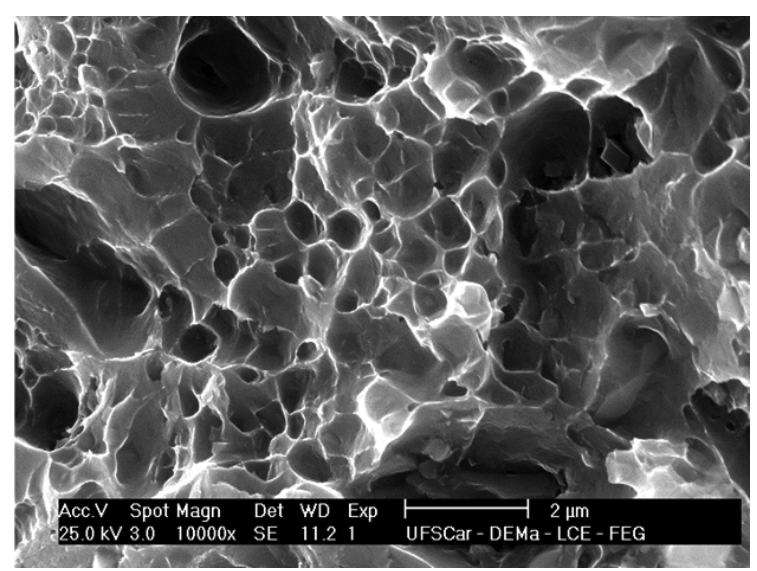

(b)

Figure 7. SE/SEM micrograph of a fractured surface of the tensile test specimen (a) and white box detail in (b).

micrograph of a fractured surface of the tensile test specimen (a) and white box detail in (b).

Further development was performed with direct hot extrusion at $300{ }^{\circ} \mathrm{C}$ by using several ram speeds $(3,6,9$, 18 and $24 \mathrm{~mm} / \mathrm{min}$ ) for a complete cycle of analysis since remelting up to artificial aging, aiming a T6 condition. The assessment of microstructural evolution via OM - Figure 8, has revealed recovered and coarse grains with average grain size of $50 \mu \mathrm{m}$. That might have had a strong correlation on the reduction of measured tensile properties when compared with the values of as-extruded condition and AMS $4050 \mathrm{H}$, which has represented values below $50 \%$ for extrusions at $300{ }^{\circ} \mathrm{C}(573 \mathrm{~K})$ with ram speeds of 9,18 and $24 \mathrm{~mm} / \mathrm{min}$ - Figure 9.

An induced plasma optical emission spectrometer chemical analysis (ICP OES) was used in order to determine the main alloy constituents after spray forming and compare with initial condition, as received from supplier. Table 1 presents these values for copper, magnesium, zinc, zirconium, and $\mathrm{Zn} / \mathrm{Mg}$ ratio. The results of the chemical analysis show that the remelting and spray forming processes led only to a small reduction on the magnesium content (approximately 10\%). All others elements do not show a significant variation exceeding the standard variation of technique employed for the determination of the chemical composition (ICP OES).

Brinell hardness measurement has revealed a hardness peak for the sample withdrawn after 16 hours at $121^{\circ} \mathrm{C}$ of artificial aging for extrusions at $300{ }^{\circ} \mathrm{C}$ and ram speeds of 3 and $6 \mathrm{~mm} / \mathrm{min}$ - Figure 10. Artificial aging curves for direct hot extrusion for two ram speeds ( $3 \mathrm{~mm} / \mathrm{min}$ and $6 \mathrm{~mm} / \mathrm{min}$ ) and ECAP.. The change in ram speed did not have significant effect on mechanical properties, via hardness Brinell measurements, and microstructure. 


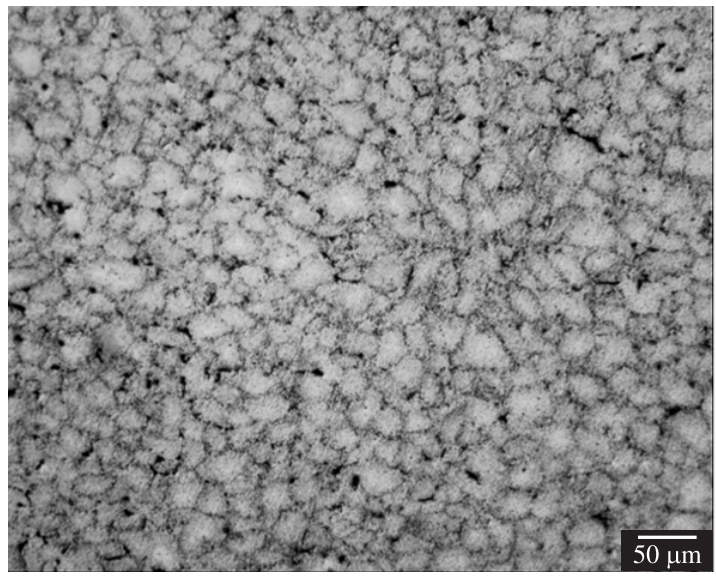

(a)

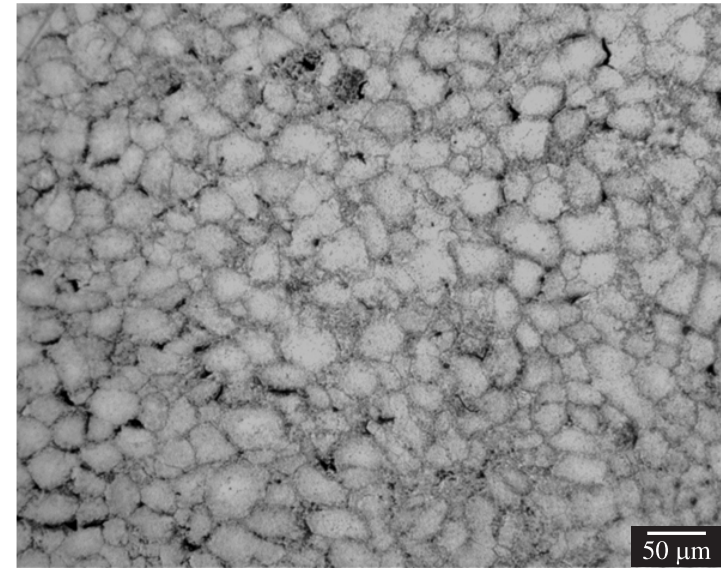

(b)

Figure 8. OM of specimen cross section in as-extruded condition (a), and after 20 hours of artificial aging at $121{ }^{\circ} \mathrm{C}$. Etchant Keller.

Tensile properties after direct hot extrusion at three different RAM speeds

$(9,18$, and $24 \mathrm{~mm} / \mathrm{min})$ and artificial aging $\left(121^{\circ} \mathrm{C}\right.$ for 24 hours $)$

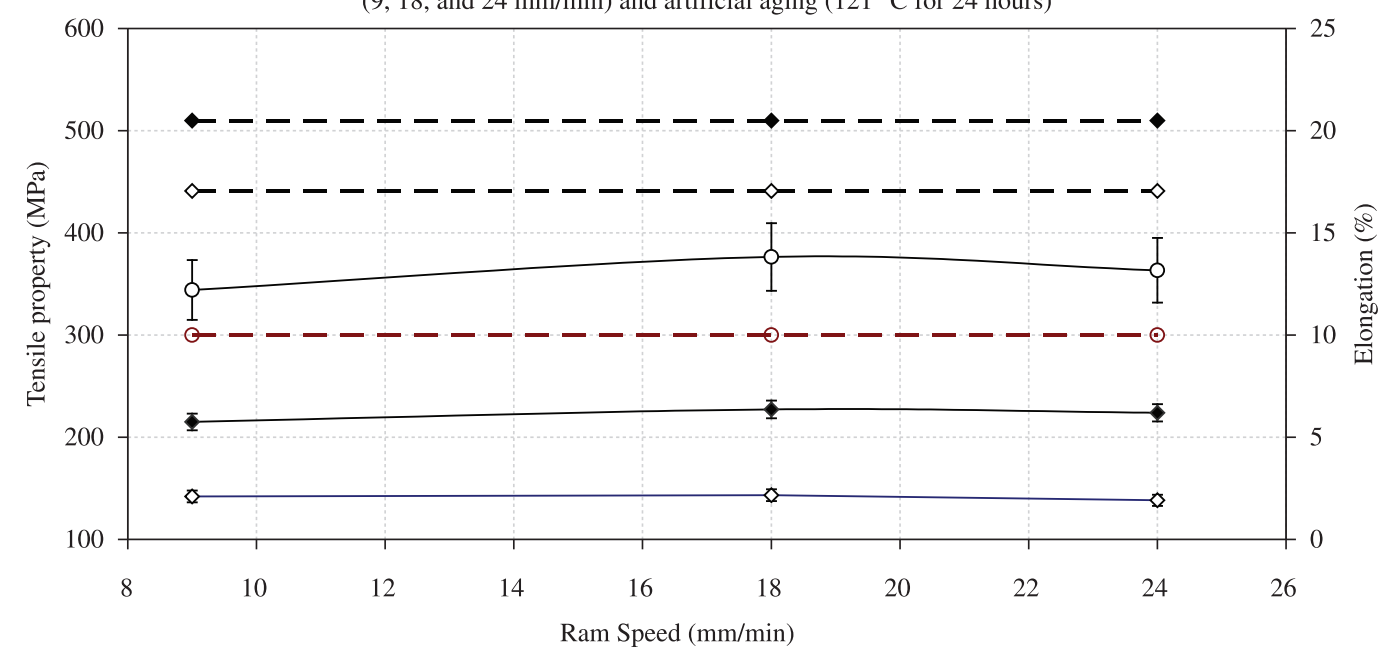

$\begin{array}{lll}\longrightarrow-\text { Tensile Strenght (MPa) Average } & \multimap \text {-Yield Strenght (MPa) Average } & \longrightarrow \text { AMS 4050 H - Tensile Strength (MPa) } \\ \prec-\text { AMS } 4050 \mathrm{H} \text { - Yield Strength (MPa) } & \multimap-\text { Elongation (\%) Average } & - \text { - AMS 4050H - Elongation (\%) }\end{array}$

Figure 9. Tensile properties for three different ram speeds $(9,18$, and $24 \mathrm{~mm} / \mathrm{min})$ and 24 hours artificial aging at $121{ }^{\circ} \mathrm{C}$.

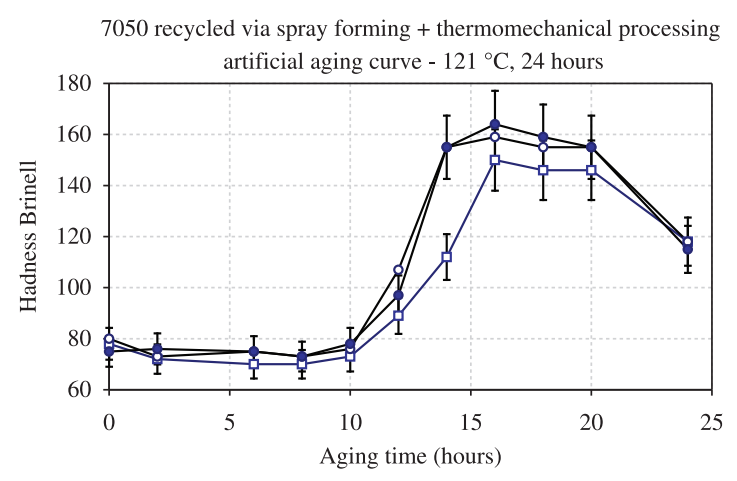

-ㅁ- SF + Homogenisation + ECAP BC $3 \mathrm{~mm} / \mathrm{min}$ -o $\mathrm{SF}+\mathrm{EXTR} 300^{\circ} \mathrm{C} 3 \mathrm{~mm} / \mathrm{min}$ $\rightarrow$ SF + EXTR $300^{\circ} \mathrm{C} 6 \mathrm{~mm} / \mathrm{min}$

Figure 10. Artificial aging curves for direct hot extrusion for two ram speeds $(3 \mathrm{~mm} / \mathrm{min}$ and $6 \mathrm{~mm} / \mathrm{min})$ and ECAP.

\subsection{ECAP}

Considering the former data obtained and the intrinsic potentialities of ECAP process, a sprayforming post-processing route was designed aiming to merge the good features from thermo-mechanical processing with heat treatment. After ECAP the samples were submitted to homogenization ( 4 hours at $420{ }^{\circ} \mathrm{C}$ followed by 8 hours at $470{ }^{\circ} \mathrm{C}$ ) Figure 11. Specimen cross section microstructure after ECAP (a) and after homogenization, and 16 hours artificial aging at $121{ }^{\circ} \mathrm{C}$. Etchant Keller.a and artificial aging Figure 11. Specimen cross section microstructure after ECAP (a) and after homogenization, and 16 hours artificial aging at $121^{\circ} \mathrm{C}$. Etchant Keller.b, according to AMS $2772 \mathrm{E}^{2}$.

An optical microscopy Polyvar REICHERT-JUNG and the Image Analyzer software Buehler version 9.0 Revision 3 was used for quantitative microstructure assessment. The average grain size was reduced from $50 \mu \mathrm{m}$, for as-deposited 
condition, to $40 \mu \mathrm{m}$, after 16 hours artificial aging. The average pore diameter reduction was about $40 \%$. And the measured average porosity area reduction was about $55 \%$. After homogenization is possible to verify the grain boundaries darker than the center of grains - Figure 11. Specimen cross section microstructure after ECAP (a) and after homogenization, and 16 hours artificial aging at $121{ }^{\circ} \mathrm{C}$. Etchant Keller.a, but after artificial aging, the grain boundaries of coarsened grains are sharply defined and the porosity is more evident inside grains - Figure 11. Specimen cross section microstructure after ECAP (a) and after homogenization, and 16 hours artificial aging at $121{ }^{\circ} \mathrm{C}$. Etchant Keller.b. It seems that during artificial aging the grains has coarsened and the grain boundaries advanced where used to have a pore between grains and at grain boundaries.

Table 1. Chemical composition variation using the sprayforming process.

\begin{tabular}{|c|c|c|c|c|c|c|}
\hline \multirow{2}{*}{ Composition (\%) } & \multicolumn{2}{|c|}{ AMS 4050H } & \multirow{2}{*}{$\begin{array}{c}\text { Manufacturer } \\
\text { certificate }\end{array}$} & \multirow{2}{*}{$\begin{array}{l}\text { Machining } \\
\text { chip }\end{array}$} & \multirow{2}{*}{$\begin{array}{c}\text { Sprayforming } \\
\text { deposit }\end{array}$} & \multirow{2}{*}{$\Delta(\%)$} \\
\hline & Min. & Max. & & & & \\
\hline $\mathrm{Cu}$ & 2.0 & 2.6 & 2.19 & 2.29 & 2.27 & 0.02 \\
\hline $\mathrm{Mg}$ & 1.9 & 2.6 & 2.09 & 2.63 & 2.4 & 0.23 \\
\hline $\mathrm{Zn}$ & 5.7 & 6.7 & 6.18 & 5.99 & 5.96 & 0.03 \\
\hline $\mathrm{Zr}$ & 0.08 & 0.15 & 0.104 & 0.09 & 0.09 & 0.00 \\
\hline $\mathrm{Zn} / \mathrm{Mg}$ & 3.0 & 2.6 & 3.0 & 2.3 & 2.5 & -0.21 \\
\hline
\end{tabular}

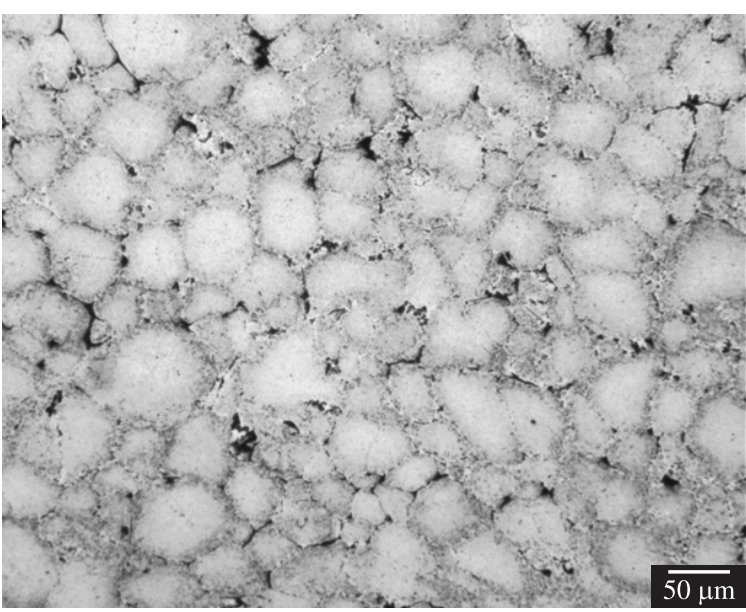

(a)

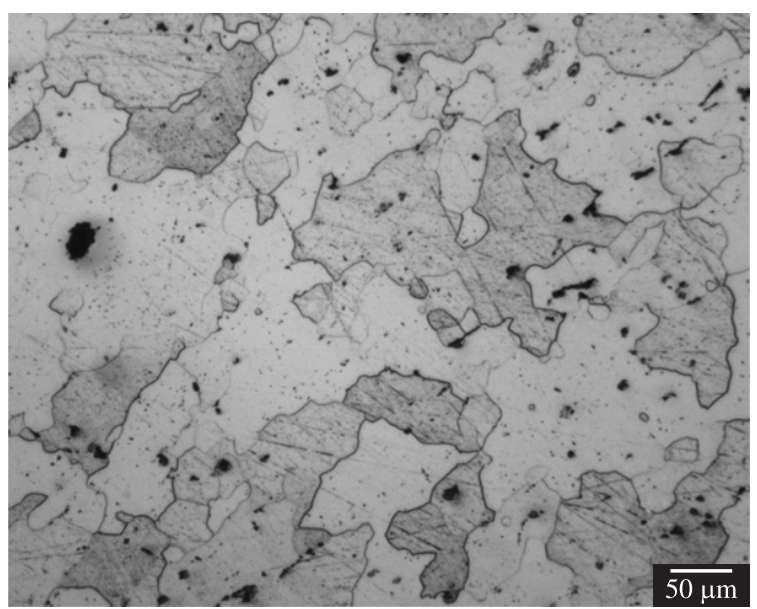

(b)

Figure 11. Specimen cross section microstructure after ECAP (a) and after homogenization, and 16 hours artificial aging at $121{ }^{\circ} \mathrm{C}$. Etchant Keller.

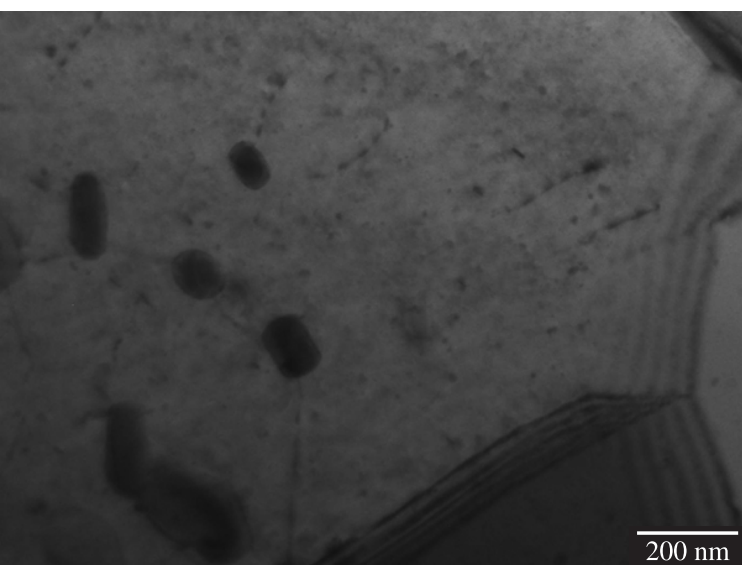

(a)

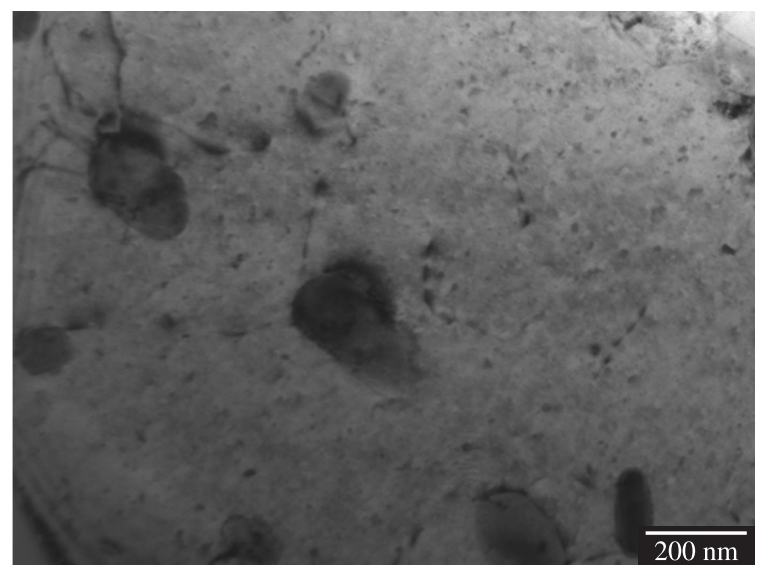

(b)

Figure 12. TEM analysis of specimens after ECAP showing defined grain boundaries and second phase particles and the presence of dislocations (a), and the interaction between dislocations and these particles in other area of the same specimen. 
A sequence of micrographies taken from ECAP specimens in as-ECAPed condition analyzed via TEM - Figure 12. TEM analysis of specimens after ECAP showing defined grain boundaries and second phase particles and the presence of dislocations (a), and the interaction between dislocations and these particles in other area of the same specimen, has revealed some second phase particles inside homogeneous grains, well defined grain boundaries, and a sequence of dislocations in the middle region of grain with decreasing spacing near grain boundary Figure 12 . TEM analysis of specimens after ECAP showing defined grain boundaries and second phase particles and the presence of dislocations (a), and the interaction between dislocations and these particles in other area of the same specimen.a, and a sequence of interaction between dislocations and second phase particles in Figure 12. TEM analysis of specimens after ECAP showing defined grain boundaries and second phase particles and the presence of dislocations (a), and the interaction between dislocations and these particles in other area of the same specimen.b.

The hardness Brinell and the average grain size evolution throughout the proposed route has shown highest hardness achieved was $176 \mathrm{HB}$ after 12 hours of artificial aging at $121{ }^{\circ} \mathrm{C}$, - Figure 10. Artificial aging curves for direct hot extrusion for two ram speeds ( $3 \mathrm{~mm} / \mathrm{min}$ and $6 \mathrm{~mm} / \mathrm{min}$ ) and ECAP. For the ram speeds used did not presented significant effect on direct hot extrusion artificial aging curves. The ECAP aging curve has hardness values lower than reached for direct hot extrusion - Figure 10. Artificial aging curves

\section{References}

1. SAE Aerospace. AMS $4050 \mathrm{H}$ : Aluminum Alloy, Plate 6.2Zn - 2.3Cu - 2.2Mg - 0.12Zr (7050-T7451) Solution Heat Treated, Stress Relieved, and Overaged. SAE Aerospace; 2003.9 p.

2. SAE Aerospace. AMS 2772E: Heat Treatment of Aluminum Alloy Raw Materials. SAE Aerospace; 2011. 24 p.

3. Watton JD. Computational modeling and optimization of bulk residual stress in monolithic aluminum die forgings. In: Proceedings of the Conference: 2010 4th Residual Stress Summit; 2010; Lake Tahoe. Lake Tahoe; 2010. 62 p.

4. Heymès F, Frankland D, Ehrström JC and Boselli J. The contribution of heavy extrusions for higher performance commercial aircraft : current new alloys in production. In: Proceedings of the Aeromat 03-HS-7449\&2027.ppt .09-06-03.

5. Heinz A, Haszler A, Keidel C, Moldenhauer S, Benedictus $\mathrm{R}$ and Miller WS. Recent development in aluminium alloys for aerospace applications. Materials Science and Engineering: A. 2000; 280:102107. http://dx.doi.org/10.1016/ S0921-5093(99)00674-7

6. Staley JT and Lege DJ. Advances in aluminum alloy products for structural applications in transportation. Journal de Physique. 1993; 3:179-190. Colloque 77, supplement au Journal de Physique III.

7. Lequeu $\mathrm{P}$, Lassince $\mathrm{P}$, Macé $\mathrm{R}$ and Warner $\mathrm{T}$. The future for aluminum in aerospace: solutions tailored for specific applications. In: Proceedings of the Aeromat 2004 Conference presentation; 2004; Seattle. Seattle; 2004. 31 p. for direct hot extrusion for two ram speeds $(3 \mathrm{~mm} / \mathrm{min}$ and $6 \mathrm{~mm} / \mathrm{min}$ ) and ECAP.

\section{Conclusions}

According to the analysis of results obtained, it is possible to state that:

- Sprayforming process is an efficient process for machining chips remelting, with possibilities for scaling up.

- Extrusion has effectiveness on porosity reduction but it has laboratory limitations for area reductions higher than 5:1, and the use of small size samples for mechanical testing.

- ECAP has an advantage of several deformation steps without changing the cross section area. But due to sprayforming deposit brittleness in as-deposit condition, only a small average grain size reduction was verified and a small reduction on porosity standard deviation.

- Homogenization and artificial aging after ECAP has resulted in growth in grain size and poor mechanical properties.

\section{Acknowledgments}

The authors wish to thank Embraer S.A.; and Post Graduate Program in Materials Science and Engineering at Federal University of São Carlos - PPG-CEM/UFSCar for supporting this project.

8. Martin R and Evans D. Reducing Costs in Aircraft: The Metals Affordability Initiative Consortium. Advanced Materials: Featured Overview. JOM. 2000; 52(3):24-28. http://dx.doi. org/10.1007/s11837-000-0096-y

9. Hinrichsen J. Alcoa Aerospace-Optimized Solutions Meeting Mission Requirements. In: Proceedings of the Aeromat Plenary Session Address; 2005; Orlando. Orlando; 2005. 17 p.

10. Schrynmakers P. Life cycle thinking in the aluminium industry. Life Cycle Performance of Aluminium Applications. International Journal of Life Cycle Assessment. 2009; 14(Suppl 1):S2-S5. http://dx.doi. org/10.1007/s11367-009-0072-x

11. Environmental Protection Agency - EPA. Compilation of air pollutant emission factors. 5th ed. EPA; $1995.12 \mathrm{p}$. Volume I: stationary point and area sources. AP-42. U.S. Research Triangle Park, NC 27711.

12. Aluminum Association. Aluminum 101.36 p. Available from: $<$ http://www.aluminum.org/AM/CM/ContentDisplay.cfm?Con tentFileID=61917\&FusePreview=Yes $>$. Access in: 25/01/2012.

13. Subodh K. Das. Designing Aluminum Alloys for a Recycling Friendly World. Trans Tech Publications, Switzerland. Materials Science Forum. 2006; 519-521:1239-1244. http:// dx.doi.org/10.4028/www.scientific.net/MSF.519-521.1239

14. Materials Case Study 2: Aluminium. In: Proceedings of the OECD Global Forum on Sustainable Materials Management; 2010; Mechelem. Mechelem; 2010. 66 p.

15. International Aluminium Institute. Global Aluminium Recycling: A Cornerstone of Sustainable Development. International Aluminium Institute; 2009. 36 p. 
16. Das SK. Presentation: Aluminum Recycling in a Carbon Constrained World: Observations and Opportunities. Observations and Opportunities. In: Proceedings of the TMS 2010. The Aluminum Industry - Perspectives on our Future. TMS - LMD Aluminum Plenary Session; 2010; Seattle. Washington; 2010. $21 \mathrm{p}$.

17. Blomberg $J$ and Söderholm P. The economics of secondary aluminium supply: An econometric analysis based on European data. Resources, Conservation and Recycling. 2009; 53(8):455-463. http://dx.doi.org/10.1016/j. resconrec.2009.03.001

18. International Aluminium Institute - IAI. Declaration by the Metals Industry on Recycling Principles. Available from: <http://www.world-aluminium.org/?pg=/Downloads/ Publications $/$ Full\%20Publication $\&$ path $=348>$. Access in: 28/01/2012.

19. Das SK, Kaufman JG, Green JAS, Phinix LLC, Lexington KY, Emadi D et al. Development of Alloy Recycling Indices for Aerospace Aluminum Alloys. In: Proceedings of the AeroMat; 2009; Dayton. ASM; 2009. 13 p.

20. Sharm MM, Amateau MF and Eden TJ. Hardening mechanisms of spray formed $\mathrm{Al}-\mathrm{Zn}-\mathrm{Mg}-\mathrm{Cu}$ alloys with scandium and other elemental additions. Journal of Alloys and Compounds. 2006; 416:135-142. http://dx.doi.org/10.1016/j. jallcom.2005.08.045

21. Valiev RZ and Langdon TG. Principles of equal channel angular pressing as a processing tool for grain refinement. Progress in Materials Science. 2006; 51:881-981. http://dx.doi. org/10.1016/j.pmatsci.2006.02.003

22. Kawasaki M, Xu C and Langdon TG. An investigation of cavity growth in a superplastic aluminum alloy processed by ECAP. Acta Materialia. 2005; 53:5353-5364. http://dx.doi. org/10.1016/j.actamat.2005.08.012

23. Furukawa M, Iwahashi Y, Horita Z, Nemoto M and Langdon TG. The shearing characteristics associated with equal-channel angular pressing. Materials Science and Engineering: A. 1998; 257:328-332. http://dx.doi.org/10.1016/ S0921-5093(98)00750-3
24. Markushev MV, Murashkin, MY, Prangnell PB, Gholinia A and Maiorova OA. Structure and mechanical behaviou of an Al-Mg alloy after equal channel angular extrusion. Nano Structured Materials. 1999; 12:39-942. http://dx.doi.org/10.1016/ S0965-9773(99)00247-0

25. Segal VM. Equal channel angular extrusion: from mechanincs to structure formation. Materials Science and Engineering: A. 1999; 271:323-333. http://dx.doi.org/10.1016/ S0921-5093(99)00248-8

26. Iwahashi Y, HoritA Z, Nemoto $M$ and Langdon TG. Na investigation of microstructural evolution during equal-channel angular pressing. Acta Materiallia. 1997; 45(11):4733-4741. http://dx.doi.org/10.1016/S1359-6454(97)00100-6

27. Cardoso KR, Travessa DN, Botta WJ, Jorge Junior M. High strength AA7050 Al alloy processed by ECAP: microstructure and mechanincal properties. Materials Science and Engineering: A. 2011; 528:5804-5811. http://dx.doi. org/10.1016/j.msea.2011.04.007

28. Embraer. Environment, Safety and Health At Work. Available from: <http://www.embraer.com/en-US/amb-responsability/ environment/Pages/home.aspx>. Access in: 25/09/2011.

29. Das SK. Designing Aluminum Alloys for a Recycling Friendly World. Materials Science Forum. 2006; 519-521:1239-1244. http://dx.doi.org/10.4028/www.scientific.net/MSF.519-521.1239

30. Das SK and Kaufman JG. Recycling Aluminum Aerospace Alloys. Light Metals. 2007. Edited by Morten Sorlie. TMS; 2007. p. 1161-1165.

31. American Society for Testing and Materials - ASTM. E 8/E 8M-08: Standard Test Methods for Tension Testing of Metallic Materials. West Conshohocken; 2008. 25 p.

32. Starink MJ and Wang SC. Amodel for the yield strength of overaged $\mathrm{Al}-\mathrm{Zn}-\mathrm{Mg}-\mathrm{Cu}$ alloys. Acta Materiallia. 2003; 51:5131-5150. http://dx.doi.org/10.1016/ S1359-6454(03)00363-X

33. American Society for Testing and Materials - ASTM. E 112-10: Standard Test Method for Determining Average Grain Size. West Conshohocken; 2010. 26 p. 